\section{In vivo electron spin resonance spectroscopy: what use is it to gastroenterologists?}

\section{N S Dhanjal, I J Cox, S D Taylor-Robinson}

Electron spin resonance (ESR) spectroscopy may have a role in the future in assessing the mucosal integrity of the colon non-invasively in the otherwise normal looking colon of patients with quiescent colitis

tike ke all techniques that strive to bridge the gap between laboratory science and clinical medicine, electron spin resonance (ESR) spectroscopy builds on established applications in biochemistry and chemistry, following on from its discovery by Professor EK Zavoisky and colleagues in 1944 at Kazan State University, situated deep within the Tatarstan Republic of the Russian Federation, formerly the Soviet Union. ${ }^{1}$ However, it is only now that developments in technology may perhaps allow the endoscopist of the future to acquire information on gut mucosal integrity in vivo during a procedure. This is an intriguing prospect, although there are a number of practical problems to be solved before the in vivo clinical potential of this sensitive and specific technology is realised. The average endoscopist, faced with the clinical burden of disease and an ever growing case load, requires an emerging clinical technique to robustly deliver reproducible clinically relevant data without obfuscation by artefact. The questions therefore arise of how feasible will it be for ESR spectroscopy to be implemented in the clinical arena and what additional information can be given to the average busy gastroenterologist?

To delve into the basic physics of the technique for a moment, ESR, also known as electron paramagnetic resonance (EPR) spectroscopy, describes the resonant absorption of microwave radiation by paramagnetic materials - that is to say, materials with an unpaired electron such as free radicals and transition metal ions-in the presence of a static magnetic field. Specifically, with respect to in vitro ESR spectroscopy, which is a well used biochemical tool, the sample is placed in a resonant chamber in a magnetic field and microwave frequency is then applied. The resulting ESR spectrum illustrates net absorption of microwaves at a specific frequency, which is dependent on the atomic and molecular structure of the sample under analysis. While an individual electron spin contributes to the magnetic moment of an atom, the majority of materials are not amenable to study by ESR spectroscopy as their electrons are paired and there is therefore no net bulk magnetism. This means that the region under scrutiny must contain a paramagnetic substance and so, for clinical applications, either a free radical must be administered or a so called "spin trap" must be utilised to provide a mechanism for detection of reactive naturally occurring free radicals, present only in very low concentrations. ${ }^{23}$ By way of comparison, nuclear magnetic resonance (NMR) spectroscopy is based on the property of nuclear spin and there are a number of similarities between these two non-invasive techniques. ${ }^{45}$ Owing to the fact that electrons have a greater magnetic moment than nuclei, ESR spectroscopy is more sensitive than NMR spectroscopy. ESR spectroscopy also has the advantage of being highly specific, although it clearly can be a disadvantage that most chemical and biological materials are not paramagnetic. ESR spectroscopy has the scope for studying faster dynamics than NMR spectroscopy as the ESR timescale in the time domain is nanoseconds and not milliseconds as in NMR. ${ }^{6}$ The ESR technique has more recently been harnessed to study the presence and generation of free radicals in intact cells, perfused organs, and in small animals in vivo. ${ }^{7-10}$ For practical purposes, ESR spectroscopy allows some measurement of free radicals. Taken to its logical conclusions in the clinical context, an endoscope with ESR spectroscopy capabilities could, for example, be of use for surveillance when the mucosal surface may otherwise appear normal.

In this issue of Gut, Togashi and colleagues ${ }^{11}$ have used ESR spectroscopy to investigate changes in mucosal sulfhydryl compounds in an animal model of colitis [see page 1291]. These authors have previously evaluated the ESR active insight into tissue inflammation through compound 3-carbamoyl-2,2,5,5- tetramethylpyrrolidine-1-oxyl (carbamoylPROXYL) as a "spin probe" for measuring oxidative stress in the murine liver. ${ }^{10}{ }^{12}$ The same technique has been extended to experimental colitis as it was argued that adequate levels of mucosal sulfhydryl compounds, such as reduced glutathione, are critical in the prevention of tissue damage from the generation of reactive oxygen species in inflammatory conditions, such as ulcerative colitis. ${ }^{11}$ This technique provides a non-destructive method of assessing oxidative stress in small animals and these authors have produced a very elegant study using their in house, low frequency, $700 \mathrm{MHz}$ microwave ESR spectroscopy apparatus. The authors are developing new ESR spectroscopy equipment with a surface coil-type resonator, which may be applicable to clinical colonoscopy.

The development of low frequency ESR spectroscopy, combined with the introduction of surface coil-type resonators, has opened up a wide range of applications for ESR as the depth sensitivity of the technique has improved and the required sample size is less restricted by the dimensions of the resonator. ${ }^{13}{ }^{14}$ Furthermore, methods of reducing artefacts from voluntary and involuntary motion are being addressed..$^{15}$ As with all new techniques, safety issues must be considered as magnetic fields and microwave power are integral to the ESR spectrometer, albeit at low levels, and because paramagnetic materials may be administered. The current generation of ESR spectrometers have quite limited physical space, as illustrated in the equipment used in the study of Togashi and colleagues, ${ }^{11}$ and therefore larger magnets are required for interventional clinical applications. With regard to the development time to clinical usage, there are some parallels with NMR spectroscopy. The NMR phenomenon itself was discovered shortly after World War II, but it was not until the mid-1980s that human NMR spectroscopy studies started on liver and in muscle using whole body magnets. ${ }^{16}{ }^{17}$ In that sense, NMR spectroscopy was ahead of the game compared with ESR spectroscopy but there were still many years of proving the value of NMR spectroscopy before clinical studies were undertaken in earnest. ${ }^{18}{ }^{19}$ In fact, for gastroenterologists, the liver remains the main focus of interest for NMR spectroscopy as in vivo studies on the gut are fraught with technical difficulties whereas the liver as a solid organ is a much easier focus for NMR study. ${ }^{20} 21$ Therefore, having an endoscope with in built NMR spectroscopy capabilities is still on the drawing board, rather than being a practical reality.

Returning to the problem in hand, the study by Togashi et al illustrates that it 
could be very desirable to have ESR spectroscopy capabilities for a new generation of future endoscopes in order to assess the mucosal integrity of the colon non-invasively in the otherwise normal looking colon of patients with quiescent colitis. However, so that this goal can become a reality, a range of safety and practical issues need to be overcome, obviously initially in the domain of research institutes where clinician scientists can conduct small scale research studies on selected patients with specialist equipment. While there are some potential pitfalls, we do suggest that you follow the development of clinical ESR spectroscopy enthusiastically. Nevertheless, it remains to say that time will tell whether the technique becomes sufficiently robust to join the diagnostic armamentarium of the busy clinical gastroenterologist

\section{Gut 2003;52:1236-1237}

\section{Authors' affiliations}

N S Dhanjal, Department of Medicine A Division of Medicine, Imperial College London, Hammersmith Hospital Campus, London, UK I J Cox, Robert Steiner Magnetic Resonance Unit, Imaging Sciences Department, MRC Clinical Sciences Centre, Faculty of Medicine, Imperial College London, Hammersmith Hospital Campus, London, UK

S D Taylor-Robinson, Department of Medicine A, Division of Medicine, and Robert Steiner Magnetic Resonance Unit, Imaging Sciences Department, MRC Clinical Sciences Centre, Faculty of Medicine, Imperial College London Hammersmith Hospital Campus, London, UK
Correspondence to: Dr S D Taylor-Robinson, Gastroenterology Unit, Imperial College London, Hammersmith Campus, Du Cane Rd, London W12 OHS, UK; s.taylor-

robinson@imperial.ac.uk

\section{REFERENCES}

Abragam A, Bleaney B. Electron Paramagnetic Resonance of Transition lons. Oxford: Clarendon Press, 1970.

2 Swartz HM. Measuring real levels of oxygen in vivo: opportunities and challenges. Biochem Soc Trans 2002; 30:248-52.

3 Berliner LJ, Khramtsov V, Fujii H, et al. Unique in vivo applications of spin traps. Free Radic Biol Med 2001;30:489-99.

4 Bloch F, Hansen WW, Packard M. The nuclear induction experiment. Phys Rev 1946;70:136-42.

5 Purcell EM, Torrey HC, Pound RV. Resonance absorption by nuclear moments in a solid. Phys Rev 1946;69:37-8.

6 Borbat PP, Costa-Filho AJ, Earle KA, et al Electron spin resonance in studies of membranes and proteins. Science 2001;291:266-9.

7 Liu XT, Hu J. Relationship between bilirubin free radical and formation of pigment gallstone. World J Gastroenterol 2002;8:413-17

8 Zweier JL, Kuppusamy P. Electron paramagnetic resonance measurements of free radicals in the intact beating heart: a technique for detection and characterization of free radicals in whole biological tissues. Proc Natl Acad Sci U S A 1988;85:5703-7.

9 Halpern HJ, Yu C, Barth E, et al. In situ detection by spin trapping of hydroxyl radical markers produced from ionising radiation in the tumour of a living mouse. Proc Natl Acad Sci U S A 1995:92.796-800.

10 Togashi H, Shinzawa H, Matsuo T, et al. Analysis of hepatic oxidative stress status by electron spin resonance spectroscopy and imaging. Free Radic Biol Med 2000:28:846-53.

11 Togashi H, Oikawa K, Adachi T, et al. Mucosal sulfhydryl compounds evaluation by in vivo electron spin resonance spectroscopy in mice with experimental colitis. Gut 2003:52:1291-6.

12 Togashi H, Matsuo T, Shinzawa H, et al. In vivo imaging of increased oxidative stress in the liver by electron spin resonance-computed tomography. Res Commun Mol Pathol Pharmacol 2000;107:197-217.

13 Berliner LJ, Fujii $\mathrm{H}$, Wan XM, et al. Feasibility study of imaging a living murine tumor by electron paramagnetic resonance. Magn Reson Med 1987;4:380-4.

14 Lin $\mathrm{Y}$, Yokoyama $\mathrm{H}$, Ishida $\mathrm{S}$, et al. In vivo electron spin resonance analysis of nitroxide radical injected into a rat by a flexible surface-coil-type resonator as an endoscopeor a stethoscope-like device. Magn Reson Mater Phys 1997:5:99-103.

15 Hirata H, Walczak T, Swartz HM. Electronically tunable surface-coil-type resonator for L-band EPR spectroscopy. $J$ Magn Reson 2000:142;159-67.

16 Cox IJ. Development and applications of in vivo clinical magnetic resonance spectroscopy. Prog Biophys Molec Biol 1996;65:45-81.

17 Taylor-Robinson SD. Applications of magnetic resonance spectroscopy to chronic liver disease. Clin Med 2001;1:54-60.

18 Cox IJ, Menon DK, Sargentoni J, et al. Phosphorus-31 magnetic resonance spectroscopy of the human liver using chemical shift imaging techniques. J Hepatol 1992; 14:265-75.

19 Jalan R, Sargentoni J, Coutts GA, et al Hepatic phosphorus-31 magnetic resonance spectroscopy in primary biliary cirrhosis and its relation to prognostic models. Gut 1996;39:141-6.

20 Changani KK, Jalan R, Cox IJ, et al. Evidence for altered hepatic gluconeogenesis in patients with cirrhosis using in vivo 31 -phosphorus magnetic resonance spectroscopy. Gut 2001;49:557-64

$21 \operatorname{Lim}$ AK, Patel N, Hamilton G, et al. The relationship of in vivo ${ }^{31} \mathrm{P} M R$ spectroscopy to histology in chronic hepatitis C. Hepatology 2003;37:788-94.

\section{Keeping neuroendocrine cells in check: roles for TGF $\beta$, Smads, and menin?}

\section{G J Dockray}

Neuroendocrine tumour cells of the gastroenteropancreatic tract are subject to paracrine and autocrine growth inhibition by transforming growth factor $\beta$ which may account for the low cell proliferation of this tumour

$\mathrm{T}$ he endocrine cells of the gastrointestinal epithelium sense the luminal contents and through secretions at their basolateral side signal both to other epithelial cells and to subepithelial cells, including smooth muscle, neurones, and inflammatory cells. ${ }^{1}$ Some of the features of these cells are clearly neuronelike and for a time it was thought that during development they might be derived, like enteric neurones, from the neural crest. This now seems unlikely, and instead it is thought that normally they arise from the pluripotent stem cells that also give rise to the other epithelial cell lineages. ${ }^{2}$ However, in some circumstances at least, these cells appear to have the capacity for proliferation, and in extreme cases this gives rise to tumours that are called "neuroendocrine" as they exhibit some of the features of neurones and endocrine cells. There are many similarities between neuroendocrine tumours of the gastrointestinal tract and pancreas. In general, these tumours grow slowly and the reasons for this are unknown. Wimmel and colleagues ${ }^{3}$ now present evidence that transforming growth factor $\beta$ (TGF $\beta$ ) is produced by neuroendocrine tumours and through autocrine and paracrine mechanisms restrains tumour cell proliferation [see page 1308].

There are over a dozen major enteroendocrine cell (EEC) types, most with a restricted distribution along the gut. ${ }^{1}$ The cellular mechanisms that normally determine the differentiation of these cells, and their numbers relative to other epithelial cells in each region of the gut, are only now becoming clear. For example, the basic helix-loop-helix (bHLH) transcription factor neurogenin 3 is required for the development of intestinal and pancreatic endocrine cells and for the main pyloric antral endocrine cells ( $G$ and $D$ cells), but not for endocrine cells of the gastric corpus such as enterochromaffin-like (ECL) and $\mathrm{X}$ 
cells. ${ }^{45}$ Another bHLH transcription factor, BETA2/NeuroD, is required for the development of intestinal secretin and cholecystokinin cells. ${ }^{6}$ In contrast, the bHLH transcriptional repressor Hesl is a negative regulator of endocrine cell numbers and in mice with deletion of the Hesl gene there is hyperplasia of pyloric antral and intestinal endocrine cell populations. ${ }^{7}$

The extent to which the mechanisms determining EEC differentiation also play a part in the EEC hyperplasias found in different clinical conditions remains uncertain. Clear examples of EEC hyperplasia in patients include ECL cell hyperplasia in hypergastrinaemia, ${ }^{8} \quad \mathrm{G}$ cell hyperplasia in achlorhydria, ${ }^{9}$ and rectal EEC hyperplasia in Campylobacter enteritis. ${ }^{10}$ Of these, ECL cell hyperplasia in the gastric corpus is probably the best understood. Thus hypergastrinaemia in several different clinical settings, including gastrinoma, pernicious anaemia, and prolonged acid suppression with proton pump inhibitors, is associated with ECL cell hyperplasia. ${ }^{112}$ Similarly, ECL cell hyperplasia occurs in rats with prolonged hypergastrinaemia (either endogenous or exogenous ). ${ }^{13}{ }^{14}$ There is direct experimental evidence in the rat to indicate that in hypergastrinaemia ECL cells have the capacity to proliferate. ${ }^{15}$ Whether this occurs normally in people is uncertain. However, it is clear that in both patients and experimental animals, hypergastrinaemia is also associated with ECL cell dysplasia and with a tendency to develop ECL cell carcinoid tumours. Moreover, there is evidence that in the setting of pernicious anaemia these tumours may regress after antrectomy compatible with the view that gastrin provides a primary drive to proliferation. ${ }^{16}$

At the cellular level, a clue to the mechanisms that might regulate the proliferation of neuroendocrine tumour cells is provided by observations in multiple endocrine neoplasia type 1 (MEN-1). Endocrine tumours of the MEN-1 syndrome may arise in several organs, particularly the pancreas, parathyroid, and pituitary glands. In addition, loss of heterozygosity $(\mathrm{LOH})$ at the locus of the menin gene occurs in about $75 \%$ of ECL cell carcinoid tumours in patients with gastrinoma on a background of MEN-1, compared with $<15 \%$ of patients with ECL cell carcinoids on a background of hypergastrinaemia due to chronic atrophic gastritis. ${ }^{17}$ Interestingly, $\mathrm{LOH}$ at this locus was not observed in mid and hindgut carcinoid tumours. ${ }^{17}$ These observations implicate the product of the menin gene in the inhibition of proliferation of both pancreatic and gastric endocrine tumours. The relevant protein, menin, binds several signalling proteins, including the transcription factors Jun-D and Smad3. ${ }^{18}{ }^{19}$ Smad3 is a downstream mediator of TGF $\beta$ signalling, and as loss of menin appears to downregulate Smad3 function, it seems reasonable to suppose that TGF $\beta$ might be a negative regulator of proliferation in at least some neuroendocrine tumours. The idea is attractive not least because TGF $\beta$ is known to inhibit the proliferation of other cells.

The data reported by Wimmel et al support the idea that TGF $\beta$ inhibits neuroendocrine tumour cell proliferation. The authors showed by immunohistochemistry that TGF $\beta 1$ was expressed in $50-80 \%$ of fore, mid, and hindgut neuroendocrine tumour cells as well as by mesenchymal cells, and that the two relevant receptors, TGF $\beta R$ I and TGF $\beta$ R II, were also highly expressed by these tumours. There was similar expression in two neuroendocrine cell lines (BON cells, from a functional human pancreatic neuroendocrine tumour, and LCC-18 cells from a non-functional colorectal neuroendocrine tumour) and in these cells TGF $\beta$ was shown to increase p2 $\mathrm{l}^{\text {(WAFI) }}$ and decrease c-myc, causing arrest in the Gl phase of the cell cycle. Moreover, neutralising antibodies to TGF $\beta$, or transfection with a dominant negative receptor, increased proliferation of responsive neuroendocrine cell lines. ${ }^{3}$

Taken as a whole, these findings provide direct evidence for the importance of TGF $\beta$ as a paracrine/autocrine inhibitor of neuroendocrine tumour cell proliferation. The findings are generally compatible with data in other systems that indicate inhibition of proliferation by TGF $\beta$ mediated by the Smad pathway and directed at decreased expression of c-myc and induction of $\mathrm{p}^{2} \mathrm{l}^{\text {(WAFl) }}$ and p $15^{\text {INK4B }}$. $^{20} 21$ The role of TGF $\beta$ in tumorigenesis is however more complicated. In particular, in other cancers it is now clear that TGF $\beta$ can act both as an enhancer of tumour progression as well as a suppressor. The picture emerging over the last few years indicates that TGF $\beta$ also stimulates tumour cell migration, promotes epithelial to mesenchymal transition (EMT), and increases the production of matrix metalloproteinases (MMPs); together these effects lead to tumour cell invasion and metastasis. ${ }^{21}$ Interestingly, while the Smad signalling pathway appears to be required for inhibition of proliferation, other signalling systems including the MAPkinase, PI-3kinase, and protein phosphatase $2 \mathrm{~A} /$ p70s6k pathways are implicated in the pro-oncogenic effects of TGF $\beta .^{20}$ The mechanisms responsible for the shift in TGF $\beta$ signalling from a tumour suppressor mode to a tumour enhancer are still unclear. Wimmel et al did not specifically address the question of whether TGF $\beta$ stimulates invasion, EMT, or expression of MMPs in neuroendocrine tumour cells. However, as these cells appear to retain the inhibitory effects of TGF $\beta$ on proliferation, they may provide a useful model for further studies of the relative importance of the tumour suppressor and pro-oncogenic actions of TGF $\beta$. Recent reports have suggested possible ways to block TGF $\beta$ signalling by delivery of soluble TGF $\beta$ receptor protein constructs. $^{22}{ }^{23}$ In experimental models, this approach appears to inhibit tumour cell invasion, and so may be valuable in preventing cancer progression. However, because suppression of neuroendocrine tumour cell proliferation by TGF $\beta$ appears to be relatively well preserved, a primary objective in this case should be the maintenance and enhancement of this action of TGF $\beta$, and care should be taken before considering whether inhibition of TGF $\beta$ is worthwhile.

Gut 2003;52:1237-1239

\section{Author's affiliation}

G J Dockray, G J Dockray, Physiological Laboratory, University of Liverpool, Crown St, PO Box 147, Liverpool L69 3BX, UK. g.j.dockray@liverpool.ac.uk

\section{REFERENCES}

Dockray GJ. Making sense of gut contents. Scand J Gastroenterol 2003 (in press).

2 Brittan M, Wright NA. Gastrointestinal stem cells. J Pathol 2002; 197:492-509.

3 Wimmel A, Weidenmann B, Rosewicz S. Autocrine growth inhibition by transforming growth factor $\beta$ - 1 (TGF $\beta$ - 1 ) in human neuroendocrine tumour cells. Gut 2003;52;1308-16.

4 Lee CS, Perreault N, Brestelli JE, et al. Neurogenin 3 is essential for the proper specification of gastric enteroendocrine cells and the maintenance of gastric epithelial cell identity. Genes Dev 2002;16:1488-97.

5 Jenny M, Uhl C, Roche C, et al. Neurogenin3 is differentially required for endocrine cell fate specification in the intestinal and gastric epithelium. EMBO J 2002;21:6338-47.

6 Naya FJ, Huang HP, Qiu Y, et al. Diabetes, defective pancreatic morphogenesis, and defective pancreatic morphogenesis, and BETA2/neuroD-deficient mice. Genes Dev 1997: 11:2323-34.

7 Jensen J, Pedersen EE, Galante P, et al. Control of endodermal endocrine development by Hes-1. Nat Genet 2000;24:36-44.

8 Bordi C, D'Adda T, Azzoni C, et al. Hypergastrinemia and gastric enterochromaffin-like cells. Am J Surg Pathol 1995; 19(suppl 1):S8-19

9 Arnold R, Frank $M$, Simon $B$, et al. Adaptation and renewal of the endocrine stomach. Scand J Gastroenterol Suppl 1992:193:20-7.

10 Spiller RC, Jenkins D, Thornley JP, et al. Increased rectal mucosal enteroendocrine cells, T lymphocytes, and increased gut permeability following acute Campylobacter enteritis and in post-dysenteric irritable bowe syndrome. Gut 2000:47:804-11.

11 Peghini PL, Annibale B, Azzoni C, et al Effect of chronic hypergastrinemia on human enterochromaffin-like cells: insights from patients with sporadic gastrinomas. Gastroenterology 2002;123:68-85.

12 Lamberts R, Creutzfeldt W, Struber HG et al. Long-term omeprazole therapy in peptic ulcer disease: gastrin, endocrine cell growth, and gastritis. Gastroenterology 1993; 104: 1356-70.

13 Tielemans $Y$, Hakanson R, Sundler F, et al Proliferation of enterochromaffinlike cells in omeprazole-treated hypergastrinemic rats. Gastroenterology 1989;96:723-9.

14 Ryberg B, Axelson J, Hakanson R, et al. Trophic effects of continuous infusion of 
[Leu 15]-gastrin-17 in the rat. Gastroenterology 1990:98:33-8.

15 Ryberg B, Tielemans Y, Axelson J, et al.

Gastrin stimulates the self-replication rate of enterochromaffinlike cells in the rat stomach. enterochromaffinlike cells in the rat stomach. Effects of omeprazole, ranitidine, and gastrin17 in intact and antrectomized rats. Gastroenterology 1990;99:935-42.

16 Higham AD, Dimaline R, Varro A, et al. Octreotide suppression test predicts beneficial outcome from antrectomy in a patient with outcome from antrectomy in a patient with Gastroenterology

17 Debelenko LV, Emmert-Buck MR, Zhuang Z, et al. The multiple endocrine neoplasia type I gene locus is involved in the pathogenesis of type II gastric carcinoids. Gastroenterology 1997: 113:773-81.

$18 \mathrm{Kaji} \mathrm{H,} \mathrm{Canaff} \mathrm{L,} \mathrm{Lebrun} \mathrm{JJ,} \mathrm{et} \mathrm{al.} \mathrm{Inactivation}$ of menin, a Smad3-interacting protein, blocks transforming growth factor type beta signaling. Proc Natl Acad Sci U S A 2001:98:3837-42

19 Poisson A, Zablewska B, Gaudray P. Menin interacting proteins as clues toward the understanding of multiple endocrine neoplasia type 1. Cancer Lett 2003;189:1-10.

20 Wakefield LM, Roberts AB. TGF-beta signaling: positive and negative effects on

\section{Inappropriate ileal conservation of bile acids in cholestatic liver disease: homeostasis gone awry}

A F Hofmann

\section{Patients with cholestatic liver disease are likely to inappropriately conserve bile acids. Ursodiol corrects the defect, but is this enough?}

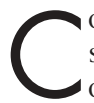
onjugated bile acids are water soluble amphipathic end products of cholesterol metabolism that promote lipid transport in the biliary tract and small intestine by forming mixed micelles. ${ }^{1}$ Bile acids are formed in pericentral hepatocytes by a complex multienzyme process whose details have at last been largely elucidated. ${ }^{2}$ After formation, their acidic group is linked ("conjugated") with the amino group of glycine or taurine in an amide bond that is resistant to the proteolytic enzymes present in pancreatic secretion and on the surface of the enterocyte brush border. Conjugated bile acids differ from unconjugated bile acids in being membrane impermeable and water soluble at the $\mathrm{pH}$ conditions prevailing in the biliary tract and small intestine.

Efficient ileal conservation of bile acids results in the accumulation of a mass of bile acids termed the bile acid "pool". Between meals, most of the pool is stored in the gall bladder; with meals, the gall bladder discharges bile into the small intestine where bile acids promote lipid absorption. Both bile acid synthesis and ileal conservation continue after a meal but the gall bladder does not increase in volume in proportion to the amount of bile acids it contains because of its continuous concentration of bile. The gall bladder appears early in vertebrate evolution and genes for gall bladder development appear to have evolved at the same time as genes for bile acid synthesis and intestinal conservation.
Development of the enterohepatic circulation and gall bladder storage resulted in far more bile acids being available for digestion than those recently synthesised. Each bile acid molecule is used multiple times before it is lost to the large intestine. ${ }^{3}$

Feedback inhibition of bile acid biosynthesis in the hepatocyte is well established experimentally. Interruption of the enterohepatic circulation causes increased bile acid synthesis. This may be modest, for example, increases of 3-4 times are seen in patients taking bile acid sequestrants for hypercholesterolaemia; or it may be marked, for example, increases of 10-15 times are seen with an ileal resection causing severe bile acid malabsorption. Bile acid feeding of any of the natural bile acids occurring in human bile (cholic acid (CA), chenodeoxycholic acid (CDCA), deoxycholic acid (DCA)) suppresses bile acid synthesis, but the effect is relatively small (about a 50\% decrease).

The mechanism by which the concentration of bile acids in the hepatocyte regulates bile acid synthesis has been elucidated only recently. Bile acids enter the nucleus and bind to a heterodimeric protein composed of two nuclear receptors, FXR and RXR. ${ }^{5}{ }^{6}$ Binding of the bile acid molecule to FXR changes its confirmation. This in turn leads to a complex sequence of events resulting ultimately in increased synthesis of one or more inhibitory proteins. The inhibitory protein(s) repress(es) the activity of the tumorigenesis. Curr Opin Genet Dev 2002:12:22-9.

21 Derynck R, Akhurst RJ, Balmain A. TGF-beta signaling in tumor suppression and cancer progression. Nat Genet 2001;29:117-29.

22 Muraoka RS, Dumont N, Ritter CA, et al. Blockade of TGF-beta inhibits mammary tumor cell viability, migration, and metastases. J Clin Invest 2002;109:1551-9.

23 Yang YA, Dukhanina O, Tang B, et al. Lifetime exposure to a soluble TGF-beta antagonist protects mice against metastasis without adverse side effects. J Clin Invest 2002; 109:1607-15 gene for cholesterol 7 alpha hydroxylase, the rate limiting enzyme in bile acid biosynthesis. ${ }^{7}$ FXR, the bile acid nuclear receptor, has now been crystallised, its structure determined by $x$ ray crystallography, and the shape of the cavity that holds the conjugated bile acid elucidated in the last few months. ${ }^{89}$

Transport of bile acids by the ileal enterocyte is also modulated in a homeostatic manner analogous to feedback inhibition of bile acid biosynthesis in the hepatocyte. Early studies of bile acid secretion at the Mayo Clinic reported that bile acid secretion increased only modestly or not at all when bile acids were fed, ${ }^{10}$ hinting at downregulation of ileal transport in response to bile acid feeding. The first convincing experimental evidence for feedback inhibition of bile acid transport was reported by Lillienau and colleagues ${ }^{11}$ who performed experiments in the guinea pig. These workers measured total ileal absorptive capacity for conjugated bile acids by perfusing bile acids at such a high rate that the intraluminal concentration remained constant. This technique had been used previously in studies that defined the $\mathrm{T}_{\max }$ for ileal transport in rats $^{12}$ and humans. ${ }^{13}$ Lillienau et al found that the ileal transport capacity for bile acids decreased after bile acid feeding and was increased by addition of cholestyramine to the diet. This finding was confirmed for the mouse, ${ }^{14}$ but using other experimental designs it was not confirmed in the rat (see Lanzini and colleagues $^{15}$ ) or in the pig. ${ }^{16}$ Thus in this area of physiology there are marked species differences, a problem that continues to bedevil those who try to understand the intricacies of bile acid metabolism. The mechanism by which the concentration of bile acids in the ileal enterocyte modulates enterocyte transport is under active investigation at the moment. As in the hepatocyte, regulation is likely to involve interaction of bile acids with nuclear receptors such as FXR. $^{17}$

Lillienau and colleagues ${ }^{11}$ speculated that "patients with cholestatic liver disease are likely to inappropriately conserve endogenous dihydroxy bile acids such as CDCA and DCA, which are 
known to be hepatotoxic". This speculation has now been confirmed in an important clinical study by Lanzini and colleagues $^{15}$ in this issue of Gut [see page 1371]. These workers used ${ }^{75} \mathrm{Se}$ SeHCAT, a selenium tagged homologue of taurocholate, whose metabolism was shown by Jazrawi et al to be essentially identical to that of taurocholate. ${ }^{18} \mathrm{Be}$ cause SeHCAT is a gamma particle emitter, it can be used to visualise the enterohepatic circulation and has been used for this purpose to measure hepatic excretory function non-invasively in patients with cholestatic liver disease. ${ }^{19}$ SeHCAT has also been used to measure the efficiency of ileal conservation of bile acids in diarrhoeal conditions. ${ }^{20}$

In the experiments reported by Lanzini et al, SeHCAT was used as a surrogate for taurocholate, and its turnover rate quantified by measuring gall bladder radioactivity daily for several days. The rate of decline in radioactivity with time gives the fractional turnover rate of the endogenous bile acid pool. The method used by Lanzini et al does not provide information on bile acid synthesis, which is the product of pool size and turnover rate. ${ }^{21}$

Lanzini et al found that the fractional turnover rate of 14 women with primary biliary cirrhosis (PBC) was, on average, one half that of 14 age matched healthy women. The $\mathrm{t}^{1} \frac{1}{2}$ (equal to 0.69 divided by the fractional turnover rate) was correspondingly increased. Thus in these patients with all stages of PBC, bile acids were inappropriately retained. The simplest interpretation of this novel finding is that the ileum has sensed a lowered intraluminal bile acid concentration and reacted by increasing its efficiency of bile acid conservation. However, a sensing of the elevated plasma level of bile acids might also contribute. In health, the ileum efficiently downregulates transport in response to increased bile acid loads thereby protecting the liver. When the bile acid pool is lost, as in acute diarrhoeal disease, the ileum upregulates to regenerate the bile acid pool as quickly as possible. In cholestatic liver disease, the signal of decreased intraluminal bile acid concentration acts to mislead the ileal transport system, which cannot know that bile acids are being retained in the hepatocyte because of biliary ductule obstruction. Inappropriate ileal conservation in cholestatic liver disease is homeostasis gone awry.

Lanzini et al made a second important observation. Inappropriate ileal conservation of bile acids was abolished by administration of ursodiol at the usual dose of $15 \mathrm{mg} / \mathrm{kg} /$ day. Although ursodiol is fairly well absorbed, it does not suppress endogenous bile acid synthesis because it does not interact with the nuclear receptor FXR. ${ }^{6}$ Thus in patients receiving ursodiol, the enterohepatic circulation has an additional input (probably $10-12 \mathrm{mg} / \mathrm{kg} /$ day) of exogenous bile acids, far exceeding endogenous bile acid synthesis (3-5 mg/kg/day). Presumably, ursodiol conjugates secreted by the liver compete for active ileal transport, thus preventing the inappropriate conservation of endogenous bile acids and restoring the fractional turnover rate to normal. Ursodiol is non-cytotoxic and has multiple effects on the hepatocyte that appear to decrease the injurious effects of retained endogenous bile acids and to promote hepatic excretory function. ${ }^{22}$

A major question remaining for the hepatologist is whether downregulation of ileal bile acid transport to its normal level by ursodiol therapy is optimal therapy in cholestatic liver disease, or whether it is desirable to decrease the efficiency of ileal conservation to a still greater degree, thereby reducing the return of bile acids to the hepatocyte that is already impacted with bile acids.

Historically, bile acid drainage was used to treat the pruritus of cholestatic liver disease..$^{23}$ When cholestyramine was introduced, it was also shown to decrease pruritus that, then and still now, is considered by many to arise from increased plasma levels of bile acids. ${ }^{25}$ Emerick and Whitiington have treated intractable pruritus in children by partial biliary diversion which prevents a fraction of secreted bile acids from reaching the ileum. ${ }^{26}$ Another surgical approach reported to be successful is ileal bypass which should have the same effect as partial biliary diversion. ${ }^{27}$ The technique of extracorporeal albumin dialysis removes plasma bile acids and also decreases pruritus. ${ }^{28} \mathrm{~A}$ new bile acid sequestrant, colesevalem, has binding properties for bile acids that are superior to those of cholestyramine and has been reported to be more effective than cholestyramine in treating cholestatic pruritus in open label studies. ${ }^{29}$ The majority of these cholestatic patients were already receiving ursodiol so that these adjuvant therapeutic approaches appear to add efficacy to that achievable by ursodiol therapy alone. All of these approaches will result in less absorption of endogenous cytotoxic bile acids so that the input of bile acids to the liver will be enriched in the recently ingested ursodiol.

The last approach to be considered is inhibition of $a s b t$, the apical transporter of the ileal enterocyte. Ileal absorption of bile acids begins with transport into the enterocyte mediated by the apical sodium dependent transporter (asbt) that has been cloned and characterised in the laboratory of Dawson..$^{30}$ Development of a potent inhibitor of asbt has been the goal of several pharmaceutical companies. ${ }^{31}$ The target disease for such an inhibitor of bile acid transport was not cholestatic liver disease, but hypercholesterolaemia, a far more prevalent problem. The rationale for the development of such inhibitors was the observation that addition of a bile acid sequestrant to a statin potentiates its hypocholesterolaemic effect by still further upregulating LDL receptor activity. ${ }^{32}$ Sequestrants are known to induce only mild bile acid malabsorption, suggesting that a potent asbt inhibitor (together with a statin) should be still more effective therapy for hypercholesterolaemia. Although these agents have been promising in animal studies, it is not clear that they will reach the market. Newer more potent statins are quite effective without adjuvant therapy; and older statins will soon become available as generic drugs. In addition, bile acid malabsorption caused by ileal blockade appears to induce diarrhoea in humans because of the cathartic effect of malabsorbed bile acids. This adverse effect has dampened the enthusiasm of the drug development groups. From a commercial standpoint, cholestatic liver disease is unlikely to ever be a target of drug development by "big pharma" because the market is tiny. Let us hope, none the less, that these new potent ileal uptake blockers will be made available to hepatologists so that their value, if any, in treating cholestatic liver disease can be assessed rigorously. The side effect of diarrhoea observed in hypercholesterolaemic patients might be less of a problem in cholestatic patients as the compensatory increase in bile acid synthesis might be dampened because of liver disease.

The paper of Lanzini et al is an importance advance in our understanding of the pathophysiology of cholestatic liver disease. The enterohepatic circulation of bile acids arose in vertebrate evolution to promote nutrition, not to deal with the problem of cholestatic liver disease. Ursodiol therapy corrects the defect in inappropriate conservation. Whether this is enough or whether we should further reduce ileal transport can be tested if the newly developed asbt inhibitors become available to the liver community. Still, all of the approaches discussed above are palliative and we must continue to seek therapeutic approaches that deal with the fundamental aetiology of these conditions, which is likely to be infectious and/or autoimmune.

Gut 2003;52:1239-1241

\section{Author's affiliation}

A F Hofmann, Division of Gastroenterology, Department of Medicine, University of California, San Diego 92093-0813, USA; ahofmann@ucsd.edu

\section{REFERENCES}

1 Hofmann AF. Bile acids: their continuing importance in liver and intestinal disease. Arch Int Med 1999;159:2647-58. 
2 Russell DW. The enzymes, regulation, and genetics of bile acid synthesis. Annu Rev Biochem 2003 (in press).

3 Hofmann AF. Intestinal absorption of bile acids and biliary constituents: the intestinal component of the enterohepatic circulation and the integrated system. In: Johnson LR, Alpers DH, Christensen J, et al, eds. Physiology of the gastrointestinal tract, vol 2, 3rd edn. New York: Raven Press, 1994:1845-65.

4 Vlahcevic ZR, Pandak WM, Stravitz RT. Regulation of bile acid biosynthesis. Gastroenterol Clin North Am 1999:28:1-25.

5 Makashima J, Okamoto AY, Repa JJ, et al. Identification of a nuclear receptor for bile acids. Science 1999;284:1285-6.

6 Parks DJ, Blanchard SG, Bledsoe RK, et al. Bile acids: natural ligands for an orphan nuclear receptor. Science 1999;284:1365-8.

7 Chiang JY. Bile acid regulation of gene expression: roles of nuclear hormone receptors. Endocr Rev 2002;23:443-63.

8 Mi L-Z, Devarakionda S, Harp JM, et al. Structural basis for bile acid binding and activation of the nuclear receptor FXR. Mol Cell 2003;11:1093-100.

9 Downes M, Verdecia MA, Roecker AJ, et al. A chemical, genetic, and structural analysis of the nuclear bile acid receptor FXR. Mol Cell 2003; 1 1: 1079-92.

10 LaRusso NF, Hoffman NE, Hofmann AF, et al. Effect of primary bile acid ingestion on bile acid metabolism and biliary lipid secretion in gallstone patients. Gastroenterology 1975:69:1301-14.

11 Lillienau J, Munoz J, Longmire-Cook SJ, et al. Negative feedback regulation of the ileal bile acid transport system in rodents. Gastroenterology 1993;104:38-46.

12 Marcus SN, Schteingart CD, Marquez ML, et al. Active absorption of conjugated bile acids in vivo: kinetic parameters and molecular specificity of the ileal transport system in the rat. Gastroenterology 1991;100:212-21.

13 Schmassmann A, Fehr HF, Locher, et al. Cholylsarcosine, a new bile acid analogue: metabolism and effect on biliary secretion in humans. Gastroenterology 1993:104:117181.

14 Torchia EC, Cheema SK, Agellon LB. Coordinate regulation of bile acid biosynthetic and recovery pathways. Biochem Biophys Res Commun 1996;225: 128-33.

15 Lanzini A, De Tavonatti MG, Panarotto B, et al. Intestinal absorption of the bile acid analogue ${ }^{75} \mathrm{Se}$-homocholic acid-taurine is increased in primary biliary cirrhosis, and reverts to normal during ursodeoxycholic acid administration. Gut 2003:52:1371-5.

16 Matsamura JS, Greiner MA, Nahrwold DL, et al. Reduced ileal taurocholate absorption with total parenteral nutrition. J Surg Res 1993;54:517-22.

17 Chen F, Ma L, Dawson PA, et al. Liver receptor homologue- 1 mediates species- and cell line-specific bile acid-dependent negative feedback regulation of the apical sodiumdependent bile acid transporter. J Biol Chem 2003;278: 19909-16.

18 Jazrawi RP, Ferraris R, Bridges $C$, et al. Kinetics for the synthetic bile acid ${ }^{75}$ selenohomocholic acid-taurine in humans: comparison with $\left[{ }^{14} \mathrm{C}\right]$ taurocholate. comparison with $\left[{ }^{4} \mathrm{C}\right]$ taurocholate.

19 de Caestecker JS, Jazrawi RP, Nisbetta JA, et al. Direct assessment of the mechanism for a raised serum bile acid level in chronic liver disease. Eur J Gastroenterol Hepatol 1995; 7:955-61.

20 Fellous $K$, Jian $R$, Hanniche $M$, et al. Measurement of ileal absorption of bile salts with the selenium 75 labeled homotaurocholic acid test. Validation and clinical significance. Gastroenterol Clin Biol 1994; 18:865-72.

21 Hoffman NE, Hofmann AF. Measurement of bile acid kinetics by isotope dilution in man. Gastroenterology 1974;67:314-23.

22 Paumgartner G, Beuers U. Ursodeoxycholic acid in cholestatic liver disease: mechanisms of action and therapeutic use revisited. Hepatology 2002;36:525-31

23 Varco RL. Intermittent external biliary drainage for the relief of pruritus in certain chronic disorders of the liver. Surgery 1947:21:43-5.
24 Huet PM, Rautureau M, Dhumeaux D, et al. The effects of biliary drainage in cholestatic hepatitis. Rev Med Chir Mal Foie 1970:45:271-8.

25 DiPadova C, Tritapepe R, Rovagnati P, et al. Double-blind placebo-controlled clinical trial of microporous cholestyramine in the treatment of intra- and extra-hepatic cholestasis: relationship between itching and serum bile acids. Methods Find Exp Clin Pharmacol acids. Methods
1984;6:773-6

26 Emerick KM, Whitington PF. Partial external biliary diversion for intractable pruritus and xanthomas in Alagille syndrome. Hepatology 2002;35: 1501-6.

27 Hollands CM, Rivera-Pedrogo FJ, Gonzalez-Vallina R et al. lleal exclusion for Byler's disease: an alternative surgical approach with promising early results for pruritus. J Pediatr Surg 1998;33:220-4.

28 Stange J, Hassanein TI, Mehta R, et al. The molecular adsorbents recycling system as a liver support system based on albumin dialysis: A summary of preclinical investigations, prospective, randomized, controlled clinical trial, and clinical experience from 19 centers. Artif Organs 2002; 26: 103-110.

29 Berg Cl. Use of colesevalem hydrochloride (Welchol' ${ }^{\mathrm{TM}}$ ) as a novel therapeutic agent for the management of refractory pruritus in chronic liver disease. Hepatology 2001;34:541

30 Craddock AL, Love MW, Daniel RW, et al. Expression and transport properties of the human ileal and renal sodium-dependent bile acid transporter. Am J Physio 1998;274:G157-69.

31 Telford DE, Edwards JY, Lipson SM, et al. Inhibition of both the apical sodiumdependent bile acid transporter and HMG-CoA reductase markedly enhances the clearance of $L D L$ apo B. J Lipid Res 2003;44:943-52

32 Vega GL, Grundy SM. Treatment of primary moderate hypercholesterolemia with lovastatin (mevinolin) and colestipol. JAMA

1987;257:33-8. 